\title{
Biomedical and health research: an analysis of country participation and research fields in the EU's Horizon 2020
}

\author{
Federica Gallo ${ }^{1} \cdot$ Adele Seniori Costantini $^{2} \odot \cdot$ Maria Teresa Puglisi ${ }^{1} \cdot$ Nigel Barton $^{3}$
}

Received: 7 July 2020 / Accepted: 29 October 2020 / Published online: 17 November 2020

(c) Springer Nature B.V. 2020

\begin{abstract}
We analysed the Horizon 2020 project database, currently the European Union's (EU) largest framework programme for research and innovation - nearly 80 billion euros available over 7 years (2014-2020), to estimate the amount and type of EUsupported biomedical and health research and funding distribution among EU member states and non-European countries. Out of 20,877 projects as of 14th January 2019, a total of 4865 projects were classified as human health related. Ninety-four countries/territories worldwide participated in at least one biomedical project. The EU-15 original member states showed the highest participation as project leaders/partners and for acquired funding. Strong unequal funding distribution and participation between EU-15 and the 13 newest members-with EU-15 receiving about 87\% of funding and EU-13 only $3 \%$-have been evidenced. For both EU-15 and EU-13 we detected about $20 \%$ of projects involving the public and private sectors, according to Horizon 2020 guidelines. The largest percentage of projects was in the areas of biotechnological research (28.28\%) and "basic research" (26.95\%); these two sectors together accounted for $46.99 \%$ of the total funding assigned (7.9 billion euros). Research in neurosciences and neurological diseases appeared to be an increasing study area. Neurological and mental diseases covered about $21 \%$ of projects. Epidemiological studies accounted for about $5 \%$ of the total projects and for $14 \%$ of funding. Strong correlations were shown by indicators of financial and scientific capacity to identify success rates in obtaining EU funding, making the gap between countries with strong and weak research infrastructures difficult to overcome.
\end{abstract}

Keywords Horizon 2020 Biomedical research · Country participation · Funding distribution · Research fields · Epidemiology

\section{Introduction}

The European Union (EU) funds research conducted by EU member states and wider collaborations within and outside Europe through the Framework Programmes for Research and Technological Development (FP). Previous studies which analysed earlier FPs (FP5, FP6, and FP7) have

Electronic supplementary material The online version of this article (https://doi.org/10.1007/s10654-020-00690-9) contains supplementary material, which is available to authorized users.

Adele Seniori Costantini

adelesenioricostantini@tin.it

1 Epidemiology Unit, Staff Health Direction, Local Health Authority 1 of Cuneo, Cuneo, Italy

2 Unit of Occupational and Environmental Epidemiology (Former Director, Retired), ISPRO, Florence, Italy

3 London, UK revealed a disproportionate distribution of funds among European countries [1-3] and have shown that countries with poorer economies have fewer opportunities to obtain funds whose allocation depends primarily on the excellence of research in terms of the country's investment in scientific research, network capacity building, and scientific outputs $[1,2]$. This underlines that the societal needs of European populations have not been adequately reflected in EU investments and that it would be appropriate that less advantaged countries with higher burdens of disease receive more funds in order to overcome inequalities in health $[1,4]$.

Horizon 2020 is currently the EU's largest framework programme for research and innovation with nearly 80 billion euros of funding available over 7 years (2014 to 2020). It is based on three main pillars: Excellent science, Industrial leadership, and Social challenges, this last including the "health research" area [5]. Recently, two further, specific sections have been added-'Spreading excellence \& widening participation' and 'Science with and for Society', with 
the aims of ensuring a targeted approach towards widening support for Member States and Associated Countries and building effective cooperation between science and society $[5,6]$.

We have analysed the Horizon 2020 project database with the aim of estimating the amount and type of EU-supported medical and health research and, in particular, epidemiological research. We focused on country participation and collaboration, on funds allocation by country, and on collaboration between public and private bodies.

\section{Methods}

\section{Search strategy and projects classification}

The Horizon 2020 project database is provided on-line by the EU publications office (Community Research and Development Information service-CORDIS) [7]. As of 14th January 2019, it included 20,877 projects across the three main pillars. Research projects funded by the European Research Council (ERC) — a flagship component of Horizon 2020 are included. Project funding and participating institutions have been updated to 3rd June 2019.

A project file contains such data as project title \& objectives, names and types of leading and participating institutions or firms and their countries, project duration, overall costs \& EU funding, and "programme", "topic", "call", and "funding scheme" codes. Programme and topic codes are EU classifications, which include a unique code and title, based on project funding programmes and activities. Our target data for sampling and analysing the database were the project "title \& objectives" text and the "programme \& topic" codes that we looked for in the whole database, and not only in the health research area. In respect of "title \& objectives" text we created a list of 252 keywords or expressions which were likely to identify relevant projects if matching the title and/or text. Key words were presented as Regex expressions which ensured matching for spelling variations and embedded words, where appropriate. The list of key words is available in online Appendix 1. In respect of programme \& topic codes, we created a list of the codes and marked as being "relevant" those codes whose title specifically indicated, or could not exclude, biomedical and health research (for example: we considered "H2020-EU_3_2_2_2_/Healthy and safe foods and diets for all" or "H2020-EU_1_3_2_/Nurturing excellence by means of cross-border and cross-sector mobility" to be relevant, but not "H2020-EU_2_1_5_3_/ Sustainable, resource-efficient and low-carbon technologies in energy-intensive process industries"). A little under $20 \%$ of programme codes and just over $20 \%$ of topic codes were relevant. It should be noted that, while programme codes were present in all project records, topic codes were present in only a small proportion of them.

For this initial sampling stage we adopted a computerized process which automatically excluded projects which did not have a relevant code and which assigned the remaining projects a "relevance rating". The "rating" (ranging 1 to 67) was the sum of a "word rating" (the total unique matches of the keywords with the project "title \& objectives" text) and a "code rating" (the presence of "relevant codes" in a project's data, i.e. "programme", "topic", "call", and "funding scheme" codes). In a second stage, we (FG and ASC) read projects whose relevance rating was at least 4 .

We did not read projects with lower ratings; however, we have estimated the possible loss of relevant projects by reading the objectives of a sample of 408 out of 7652 projects with a rating less than 4 . Only 10 projects of this sample were deemed relevant to the health and biomedical area, i.e. a proportion of 0.02 (95\% CI: 0.01-0.04).

We considered as "health and biomedical research projects" those addressing the areas of research covered by "Biomedical Research"- an international journal affiliated to Allied Academies that focuses on development activities conducted in the field of biomedical research related to human health [8] that is: human cell biology, developmental biology and genetics; physiology and biophysics; pharmacology; preclinical and clinical research; translational research on new diagnostic and therapeutic devices; biomedical engineering and robotics; epidemiology; bioinformatics and computational studies; health care and health systems research. Moreover, we included projects aimed at developing national and international networks and centres of excellence and alliances for promoting health and preventing diseases. Animal studies were included if their aims included the improvement of human health. Veterinary research was excluded.

A total of 4865 projects were classified as biomedical and human health related. As they were classified by two coders (FG and ASC), their inter-rater reliability was calculated through the Cohen's Kappa coefficient, rating a sample of 200 projects, which revealed a Kappa $=0.98(p$ value $<0.000$ ).

Information provided in the CORDIS database does not allow classification by medical research field through topic and programme codes which are, with few exceptions, too generic for this purpose. In order to classify projects by field, we devised a simplification of the 21 "Health categories" of the UK Clinical Research Collaboration Health Research Classification System [9]. Our classification comprises of 10 categories: Cancer; Cardiovascular (CVD) diseases (stroke included); Other chronic diseases; Neurological diseases and mental disorders; Infectious diseases; Reproductive health, childbirth, and congenital disorders; Basic research (studies that are not specific to individual diseases or conditions: 
cell biology, developmental biology and genetics; physiology and biophysics, pharmacology, neurosciences including psychology, methodological and computational studies): Biotechnological research (artificial intelligence, robotic, translational research on new diagnostic and therapeutic devices; biomedical engineering, regenerative medicine); Generic health relevance (research applicable to all diseases and conditions or to general health and well-being of individuals: health care, health service research); Other research fields (projects not applicable to the above listed categories).

We allocated to the 6 disease-specific categories (cancer, CVD, other chronic diseases, neurological diseases and mental disorders, reproductive diseases, and infectious diseases) those projects specifically focused on the disease and mentioning the disease as the main concern under investigation even if they included basic research and testing and evaluation of new biotechnologies. Vice versa, we allocated to the "basic" category those projects aimed at underpinning basic research across different pathological entities, rather than focusing on a specific disease. We allocated to the "biotechonological research" category those projects whose main goal was to develop (and commercialise) new instrumentations and biotechnologies. A certain number of projects $(\mathrm{N}=159)$ were considered very complex to fit into a unique category by one of the two coders, so that a double reading was performed (inter-rater agreement of the two coders rating these projects: Kappa $=0.58 ; p$ value $<0.000$ ).

We considered as epidemiological those studies addressing aetiology and disease modelling, epidemiological surveillance and health policy evaluation (if human population data were used), development of data-driven models to classify patients, exposures, and outcomes. We also included clinical trials (except phase 1) and intervention trials.

\section{Outcomes of interest and statistical analysis}

To describe participation, countries were grouped according to a double classification, i.e. on the basis of their geolocalization and/or shared historical and cultural roots and on the basis of their connection with the EU. We identified 10 geographical regions: Balkan region, Baltic region, Eastern Europe, Western Europe, Other European Countries, North America and Oceania, Central/South America and the Caribbean, Asia, and Africa.

Moreover the following country groups were identified according to the EU official documentation [10]: EU-15, the original 15 member states (including the United Kingdom, as Brexit occurred on 31st January 2020, a date subsequent to fund allocation for projects here included); EU-13, the 13 newest member states; Associated countries (art. 7 of H2020 Regulation); Advanced/Developed economies; Large emerging economies; Eastern Partnership; Mediterranean Partnership; and Other developing countries.
For all countries, funding rate was calculated as total EU contribution (irrespective of whether leader or partner country) per one million inhabitants. We used population sizes for year 2017 for all countries except Kosovo, for which 2016 was used [11, 12].

For member states included in groups EU-15, EU-13, and associated countries we used two World Bank statistics available for year 2017 to correlate them to project participation. In detail, we correlated: a) the number of researchers engaged in Research \& Development (hereafter 'R\&D researchers'), expressed per million inhabitants [13] and b) research and development expenditure (\% of GDP), i.e. capital and current expenditures in the four main sectors: business enterprise, government, higher education, and private non-profit [14]. Correlation was evaluated between funding rate and both $R \& D$ researchers and \% of GDP in R\&D through the Pearson coefficient $(r)$, after having assessed the Normal distribution of these variables.

To examine the type of bodies involved in the projects, institution types were categorised according to the Horizon 2020 official classification, available within the CORDIS database [7]: private for profit companies (PRC), public bodies, excluding research and education (PUB), research organisations (REC), secondary and higher education establishments (HES), other entities (OTH).

We used Microsoft Excel for data acquisition, data management, and graph generation [15]. SAS statistical software [16] was used for descriptive statistics and analysis.

\section{Results}

\section{Country participation}

The biomedical and health research projects identified $(\mathrm{N}=4865)$ represented about $23 \%$ of the projects in the database $(N=20,877)$. The EU grants to the these projects summed to a value of about 7.9 billion euros, which is approximately $10 \%$ of the total Horizon 2020 funding and $86 \%$ of the cost of the projects overall (this percentage was about $85 \%$ for EU-15, 94\% among EU-13, and 91\% among associated countries).

Ninety-four countries/territories worldwide participated in at least one Horizon 2020 biomedical and health research project. The EU-15 member states showed the highest participation both as project leaders $(\mathrm{N}=3953)$ and as number of partners involved $(\mathrm{N}=10,007)$. They also received the greatest amount of funding $(86.97 \%$, i.e. $6,913,241,388$ euros), followed by the EU associated countries ( 832 project participation as partner countries, 456 as coordinator countries, $8.63 \%$ of funding share, i.e. $685,869,257$ euros) and by the EU-13 member states (149 projects as partners, 30 
as coordinators, $3.16 \%$ of funding share, i.e. $251,037,047$ ) (Fig. 1).

The largest funding amount was achieved by the United Kingdom (UK) (which coordinated about $18 \%$ of the projects), followed by Germany, the Netherlands, France, Spain, Italy, and Sweden, with funding ranging from 1,323,649,383 to $353,636,903$ euros. However when relating funds to population size, the highest rates were achieved by the Netherlands, Iceland, and Denmark as all these countries reached a rate above 40 million euros per one million inhabitants. In the EU-13 group, the highest grants were achieved by Hungary and Poland with 60,557,723 and 56,145,392 euros, respectively; the highest rate were reached by Estonia (over 17 million euros per one million inhabitants) and Slovenia (nearly 9 million euros per one million inhabitants) (Fig. 2a). Among non-European countries, the United States received the biggest granting $(30,581,620$ euros across 75 projects as partner); the highest funding rate was achieved by Sierra Leone (over 2 million euros for 2 collaborations) (Fig. 2b).

Indicators of financial and scientific capacity to identify success rates in obtaining EU funding showed good correlations. The correlation between funding rate and $R \& D$ researchers and \% of GDP in R\&D resulted both positive, quite strong, and statistically significant: $r=0.82, p$ value $<0.0001$ and $r=0.70, p$ value $<0.0001$, respectively.

\section{Institutions involved}

An average of 3.30 countries (standard deviation: 3.23 ) were involved per project with a range from 1 to 28 countries, as well as an average of 3.46 institutions per project (standard deviation: 5.85) but with a wider range going from 1 to 117 organizations. A total of 16,836 institutions participated in the 4865 selected projects. The most represented type of institutions receiving EU funding were the "higher education establishments" (HES) followed by "private organizations" (PRC). Actually, among all country groups, HES were the most prominent institutions: 55.35\% among EU-15, 54.91\% among EU-13, 60.48\% among Associated countries, and $61.45 \%$ among the remaining countries. PRC led 682 projects and contributed substantially to funding acquisition, as their involvement (irrespectively if project leader or partner) was around 20\% in EU-15, EU-13, and Associated countries. Research organizations, public bodies (excluding research and education), and other entities altogether reached about 25\% among EU-15 and EU-13, 17\% in Associated countries, and $27 \%$ in other countries.

\section{Fields of research}

We have identified a large percentage of projects in the field of biotechnological research $(28.28 \% ; \mathrm{N}=1376)$ as well as basic research $(26.95 \% ; \mathrm{N}=1311)$; these two sectors together accounted for $46.99 \%$ of EU funding, i.e. about 3.7 billion euros. Neurosciences (including neurobiology, neurocognitive and neurobehavioral sciences) together with neurological diseases and mental disorders covered about $15 \%$ of projects $(\mathrm{N}=756)$ and of received funding (about 1.2 billion euros). Research on cancer and CVD reached 9.62\% $(\mathrm{N}=468)$ and $2.88 \%(\mathrm{~N}=140)$ of projects and acquired $8.24 \%$ and $3.46 \%$ of funding, respectively. The remaining funding was shared by other chronic diseases (6.22\%),
Fig. 1 Worldwide Horizon 2020 funding distribution, by type of country group

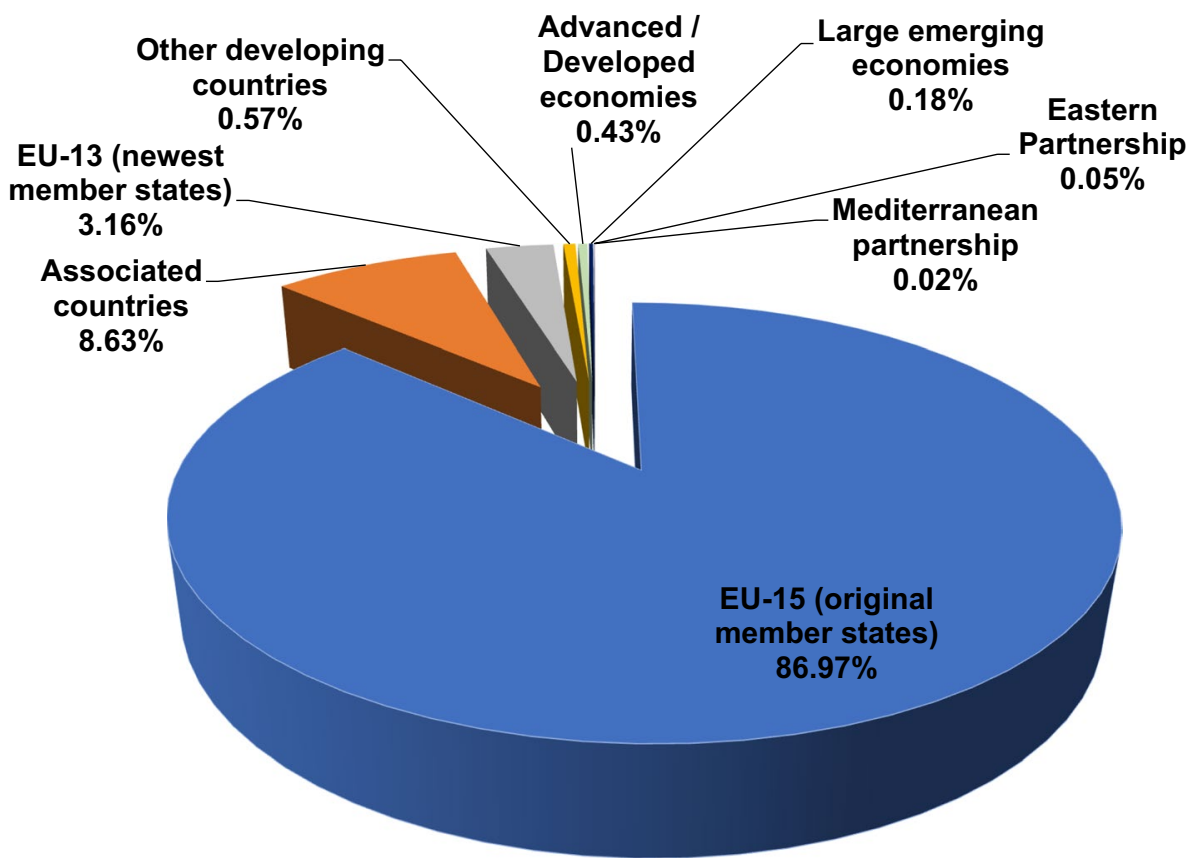


infectious diseases $(8.15 \%)$, reproductive health $(1.41 \%)$, research on generic health $(9.68 \%)$, and other research fields $(0.56 \%)$.

\section{Epidemiological studies}

Out of the 4865 biomedical and health related projects, only 235 met our criteria for being called "epidemiological".

Epidemiological studies accounted for only $4.8 \%$ of the 4865 projects, but the respective EU grants summed to a value of $1,135,742,121$ euros, thus representing about $14 \%$ of the contribution allocated to the biomedical and health research projects. The total cost of the 235 epidemiological studies was 1,500,986,473 euros, i.e. the EU financed about $75 \%$ of the whole costs.

An average of 5.09 countries were involved in the epidemiological projects with a range from 1 to 28 countries. The EU-15 member states led 213 projects which, together, accounted for $94.03 \%$ of funded epidemiological research, with the UK and the Netherlands being the more prominent countries (Table 1) for both the number of projects (51 and 36 , respectively) and grant amounts (23.68\% and $16.11 \%)$. In terms of acquired funding they were followed by Germany (11.16\%) and Italy (10.69\%).

On the base of the principal aim declared by the authors, projects have been classified as (i) observational studies (119); (ii) experimental studies of which 51 are clinical trials and 10 intervention trials; (iii) methodological studies (55). However, many studies shared multiple aims and combined different study designs.

Methodological studies included: those with deep learning techniques developed in order to better characterize and classify patients and outcomes; those aiming to monitor and harmonise the quality of data (big data), as well as to extend the techniques to countries where they are not currently available, in particular for infectious diseases; and those assessing dietary biomarkers and exposure to environmental agents.

The aims of most of the observational studies were to investigate aetiology and mechanisms of action for the most frequent diseases, as well as to identify new disease markers and new diagnostic tools. Neurological diseases and psychoneurocognitive impairment (17\%), cancer (9\%), and diabetes (3\%) constitute the most frequently investigated diseases. A large percentage of the these projects (72\%) take advantage of large repositories of data such as longitudinal population registers at regional and national level, hospital and population based disease registries, cohorts of longitudinally followed patients, with a variety of individual information (genetic and metabolic markers, disease phenotypes, lifestyles, therapies, environmental stressors, and disease outcomes). These opportunities allowed to elaborate projects aimed at predicting the risk of developing a disease, among which are genome-wide association studies.

The existence of large databases of patients affected by neurological diseases, longitudinally followed with clinical data, brain imaging, lifestyles, behavioural traits, socioeconomic status, environmental conditions, along with the genetic profile, have enabled the design of studies aimed at identifying risks and protective factors, and trajectories of disease progression. Life course perspective was also adopted to study the influence of early life factors (including the gestational period) on the mental health of children, adolescents and an aging population, as well as to examine the continuum between healthy aging and the decline of cognitive and mental health.

Even though the interplay between genes and environment was taken into consideration in many studies, only a few projects focused specifically on environmental risks $(18=8 \%)$. Even fewer, were those projects aimed at studying socio-economic differences in health $(7=3 \%)$ (access to health services, burden of diseases in minorities and disadvantaged people, and survival) There were 14 (6\%) projects which were aimed at evaluating the efficacy of policies adopted to reduce inequalities in health and lifestyles.

Out of the 51 clinical trials aimed to assess the efficacy of new therapies or new diagnostic tools, 11 pertained to CVD, 6 to cancer, and 8 to neurological diseases.

\section{Discussion}

The present study was motivated by the idea of quantifying EU funds allocation to healthcare in general and according to the various research fields, and investigating funds distribution among countries, particularly EU member states.

A good thing is that we have captured health related projects even outside the specific health research area. Beside this positive element, we recognise limitations of the approach, which, on the one hand, has included projects following calls in a limited time space (from the beginning of the call to the middle of January 2019) but, on the other hand, it may have excluded projects if matching was not optimal for the selected key terms; however, the estimate of the possible loss was very low.

The participation and grant assignments were $23 \%$ and $10 \%$ of total Horizon 2020 projects and funding, respectively. Similar results were reported by Galsworthy et al. who have estimated that about $20 \%$ of projects in FP5 and FP6 relate to human health research [2].

Six EU-15 countries (UK, Germany, Netherlands, France, Spain, and Italy) were the top funded countries receiving $66 \%$ of the total assigned funds. Our data confirm that smaller countries (such as Iceland, Denmark, Ireland, and Sweden) can be competitive with larger countries, as the 


\section{(a) European Countries}

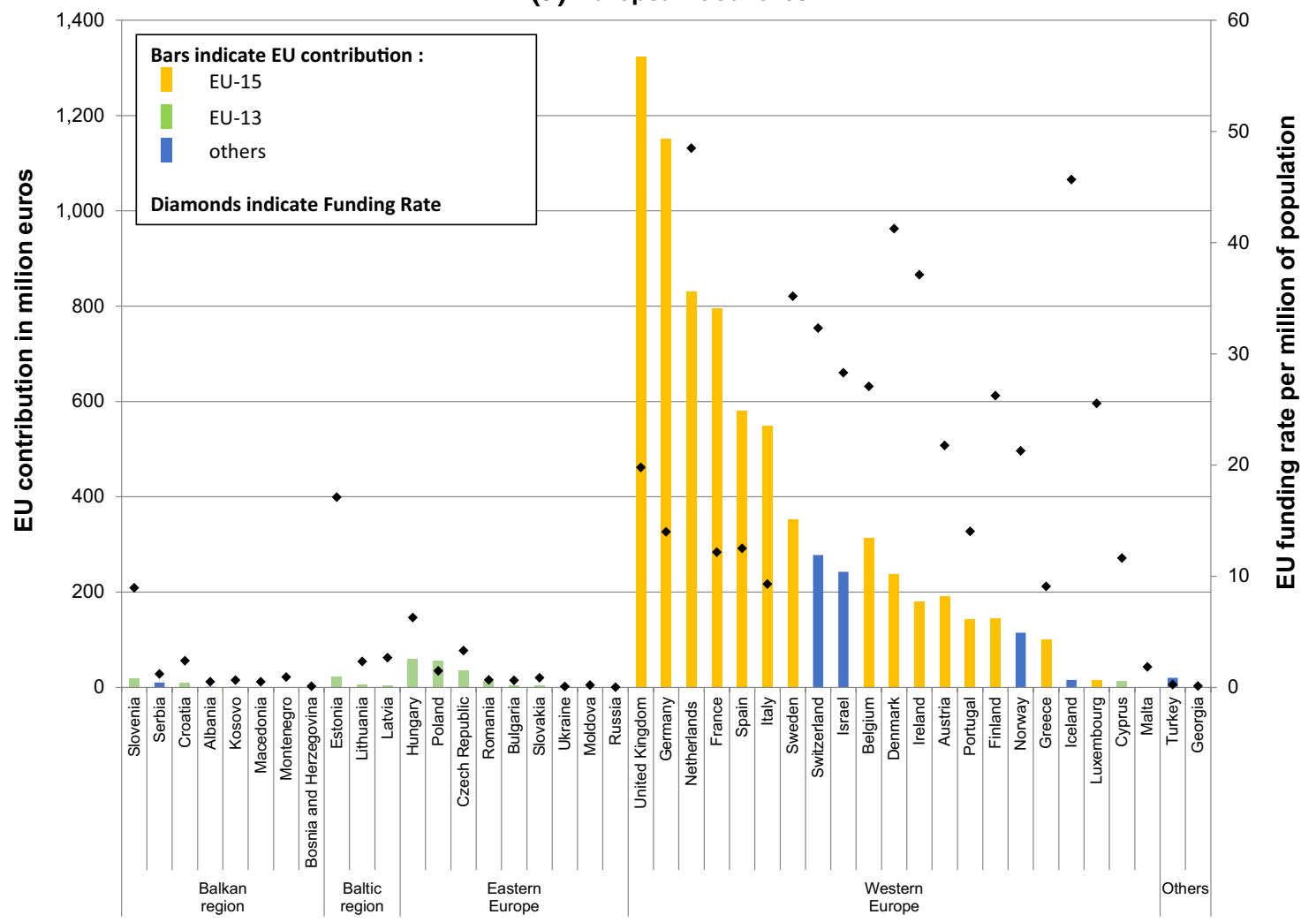

(b) Rest of the World

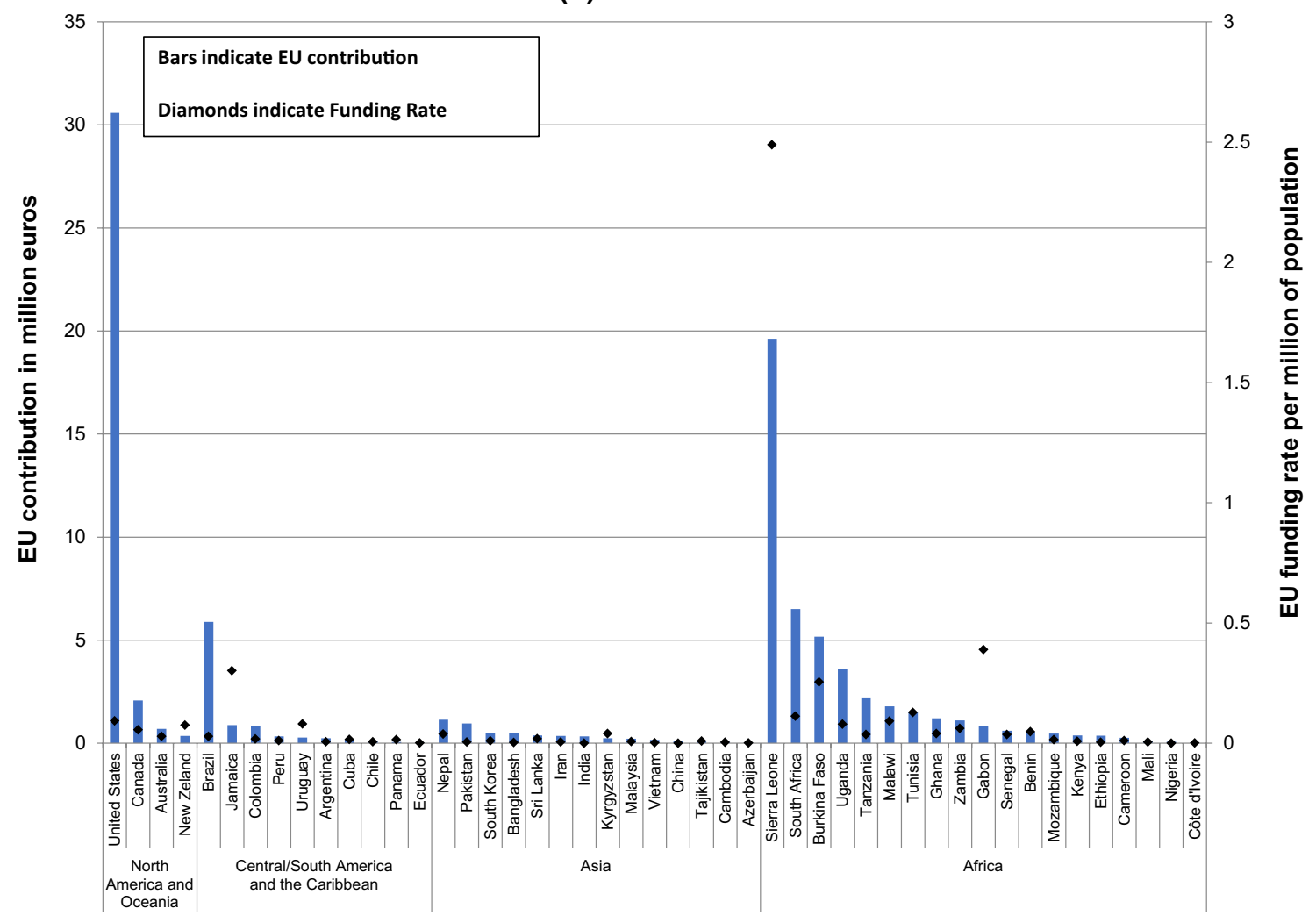


4Fig. 2 EU total contribution (both as leader or partner country) and funding rate, by decreasing contribution within geographical region across Europe (a) and the rest of the World (b)

majority of the other European countries reached higher rates when the total grant amount was weighted to the population size (with the exception of the Netherlands, which was high both in funded projects and funding rate). The same pattern was seen in the 235 epidemiological projects of which the majority were led by EU-15 countries with the United Kingdom and the Netherlands being the two top funded ones.

The unequal distribution of funding and participation between the 15 original member states and the 13 newest members, with the EU-15 receiving about $87 \%$ of Horizon 2020 funding while the EU-13 only 3\%, clearly still persists. The discrepancy is even bigger than that seen in FP5, FP6, and FP7 $[1,2,17]$. This disparity is corroborated by the fact that Associated countries placed themselves in the middle with about $9 \%$ of received funding, even though this country group includes Norway, Israel and Switzerland which are countries with a strong tradition in health project planning.

The strong correlation between funding rate and $\%$ of GDP in R\&D and between funding rate and R\&D researchers confirms results of previous studies [1,2]. Weak research infrastructures determine low participation in international conferences and then fewer opportunities to participate in international research groups and projects. The correlation between funding rate and R\&D researchers raises the disturbing issue that countries with strong teams of researchers are able to obtain more funds and these newly acquired funds facilitate the engagement of new researchers and so perpetuate the distance between poor and rich countries. The EU should work to avoid this inequality and stem the brain drain from poor to richer countries.

The EU Commission has analysed participation patterns in Horizon 2020 (2014 to 2016) in all research areas. The Commission has recognised that the research \& innovation gap in Europe remains a pressing challenge and that low national research investments and lack of access to existing networks and the clustering of large research-performing countries are key causes for low performance in EU research [18]. For this reason and with the aim of improving the final work programme running from 2018 to 2020, the specific theme "Spreading Excellence and Widening Participation" addressed to analysing causes of low performance by the EU-13 states and to fully exploit the potential of Europe's talent pool [6] has been included.

The EU parliamentary research service has reported that in FP7 $21 \%$ of all projects involved at least one EU-13 organization and in Horizon 2020 (years 2014-2015) the rate fell to $17 \%$ and has indicated policies at local, national, and European level to overcome such gaps [19].
The classification we have adopted to identify the fields of research clearly has limitations, not only because of the broad grouping, but also because of arbitrary decisions. Moreover, it does not allow us to analyse projects by research activity, so that our results do not give an exhaustive picture of the contents of the research. However, it provides an overview and allows some comparisons with other studies of the previous Framework programmes.

As far as research fields are concerned, Galsworthy et al. pointed to an increase in basic/biotechnology through subsequent calls (FP5 and FP6), which reached 39\% of total assigned funds. This trend is confirmed by our results as these two areas summed up to about $55 \%$ of analysed projects sharing about $47 \%$ of funds. Research in neurosciences and neurological diseases appears to be an increasing area of research receiving $15 \%$ of the total contribution. It has to be underlined that most of projects concerning cancer, CVD, and neurological diseases contemplate implementation of biotechnologies. It is of relevance that epidemiological projects represented $4.8 \%$ of the total biomedical and health related ones but they acquired $14 \%$ of grants.

The very limited number of studies concerning environmental risks, a probable result of little reference to environmental health research in the work programmes, is in contrast with recommendations of researchers and societies involved in epidemiology and public health who,

on the occasion of the publication of Horizon 2020, had underlined that EU funding should prioritise research on environmental risks, prevention of disease and reduction of health inequalities given that the underlying epidemic of non-communicable diseases in Europe is caused by a wide range of socio-economic and environmental factors (joint statement ISEE, EUPHA, IEA, 2014) [20, 21]. Our data show that these topics have not been prioritised in Horizon2020 while research based on medical biotechnology has been awarded.

In delivering Horizon 2020 the EU commission had recommended building cross national research and removing barriers so as to foster innovation and make it easier for public and private sectors to work together. The relevant numbers of projects involving the private sector (about 20\% in EU-15, EU-13, and Associated countries) seems to be in line with this goal concerning technological innovation in the fields of biomedicine and clinical research.

Innovation in public health research, policies and research programmes within EU countries has been described by the PHIRE project. It has been shown that only a few countries had public health research programmes and that there is limited contact among countries and between national and European research programmes and calls. It has been underlined that the EU Commission should give more emphasis to coordination of public health research among member states and to realisation of effective cooperation between science 
Table 1 Epidemiological projects and EU contribution by leading country

\begin{tabular}{|c|c|c|c|c|}
\hline \multirow[t]{2}{*}{ Leader country } & \multicolumn{2}{|c|}{ Projects } & \multicolumn{2}{|l|}{ EU contribution } \\
\hline & $\mathrm{N}$ & $\begin{array}{l}\%(\mathrm{On} \\
\text { overall } \\
\text { total })\end{array}$ & $€$ & $\begin{array}{l}\%(\mathrm{On} \\
\text { overall } \\
\text { total })\end{array}$ \\
\hline \multicolumn{5}{|l|}{$E U-15$} \\
\hline Austria & 6 & 2.55 & $20,771,804$ & 1.83 \\
\hline Belgium & 11 & 4.68 & $42,761,092$ & 3.77 \\
\hline Denmark & 9 & 3.83 & $13,831,521$ & 1.22 \\
\hline Finland & 7 & 2.98 & $24,750,193$ & 2.18 \\
\hline France & 16 & 6.81 & $76,770,278$ & 6.78 \\
\hline Germany & 19 & 8.09 & $126,432,218$ & 11.16 \\
\hline Greece & 6 & 2.55 & $33,575,382$ & 2.96 \\
\hline Ireland & 4 & 1.70 & $11,275,602$ & 1.00 \\
\hline Italy & 11 & 4.68 & $121,074,958$ & 10.69 \\
\hline Netherlands & 36 & 15.32 & $182,544,696$ & 16.11 \\
\hline Portugal & 2 & 0.85 & $4,497,000$ & 0.40 \\
\hline Spain & 22 & 9.36 & $87,652,493$ & 7.74 \\
\hline Sweden & 13 & 5.53 & $51,217,217$ & 4.52 \\
\hline United Kingdom & 51 & 21.70 & $268,270,800$ & 23.68 \\
\hline Total & 213 & 90.64 & $1,065,425,253$ & 94.03 \\
\hline \multicolumn{5}{|l|}{$E U-13$} \\
\hline Cyprus & 2 & 0.85 & $4,572,511$ & 0.40 \\
\hline Poland & 1 & 0.43 & 50,000 & 0.00 \\
\hline Total & 3 & 1.28 & $4,622,511$ & 0.41 \\
\hline \multicolumn{5}{|c|}{ Associated countries } \\
\hline Iceland & 3 & 1.28 & $5,472,036$ & 0.48 \\
\hline Israel & 5 & 2.13 & $9,538,257$ & 0.84 \\
\hline Norway & 5 & 2.13 & $23,821,987$ & 2.10 \\
\hline Switzerland & 6 & 2.55 & $24,187,988$ & 2.13 \\
\hline Total & 19 & 8.09 & $63,020,268$ & 5.56 \\
\hline Overall total & 235 & 100.00 & $1,133,068,031$ & 100.00 \\
\hline
\end{tabular}

and society [22-24]. "Public health research programmes and calls should balance calls in biomedicine in order to be responsive to the needs and priorities of the health system" [25].

Many authors have pointed to limitations in the CORDIS database in mapping and monitoring medical research as well as in sharing its outputs, emphasizing that transparency is necessary to evaluate whether funding priorities are related to societal needs and to burden of disease of European countries and whether funded research has produced information useful to improve the health of European citizens [26-28] .

A classification system that offers multiple matching keys and which allows projects to be classified not only by disease category but also by level of research and risk factors would be appropriate, as has been highlighted by many authors, in order to allow critical assessment of funds allocation. It has also been underlined that good research mapping would require a classification system common to different funders and that good informatics is fundamental to have a showcase of research and its outputs $[2,25]$.

Recently CORDIS has included a hierarchical taxonomy for fields of science which represents all the main fields of science that were discovered from CORDIS content and organised through a semi-automatic process. Some 160 terms have been identified which concern health and medicine [29]. This work, which hopefully will contribute to sound mapping of medical research, is still in progress.

While writing this text, the SARS-COVID19 pandemic has broken out in Europe and around the world. The EU, together with the WHO and other partners, hosted an international pledging conference on 4 May 2020 raising 7.4 billion euros as initial funding to kick-start a global research cooperation. The pledging continues and funds collected will be channelled into three strands: diagnostics, treatments and vaccines. This is already encouraging fast track paper publications, that will probably increase at higher rates than has ever happened in other research fields, in order to help both scientists and policy makers in engaging with directives to contain the COVID19 burden and then in providing behavioural guidelines to the population [30].

Finally, the European Commission has published its plans for "Horizon Europe" which is the next research and innovation framework programme designed for the strategic underpinning of scientific and technological progress for 2021-2027. The initial plan was to allocate 7.7 billion euros of Europe's proposed budget of 100 billion euros to health research (with a lower percentage of funds for 'health' than Horizon 2020) [31, 32]. An increase in health funding is required to directly address the complex health challenges that face European citizens in a global context, of which the COVID19 pandemic represents an undeniable example.

Authors contribution Study design; data interpretation; drafting of the manuscript (ASC); Statistical analysis and data interpretation, contribution to drafting the manuscript (FG); Data acquisition; database construction, contribution to drafting the manuscript (NB); Contribution to graphical charts creation (MTP). All authors approved the final version of the manuscript.

Funding The work has been supported by the Local Health Authority 1 of Cuneo, Italy (ASL CN1).

Availability of data and material Row data are available from authors on reasonable request.

Code availability Code is available from authors on reasonable request. 


\section{Compliance with ethical standards}

Conflict of interest The authors declare that they have no conflict of interest.

\section{References}

1. Kaló Z, van den Akker LHM, Vokó Z, Csanádi M, Pitter JG. Is there a fair allocation of healthcare research funds by the European Union? PLoS ONE. 2019;14(4):e0207046.

2. Galsworthy MJ, Irwin R, Charlesworth K, Ernst K, Hristovski D, Wismar M, McKee M. An analysis of subject areas and country participation for all health-related projects in the EU's FP5 and FP6 programmes. Eur J Public Health. 2014;24(3):514-20. https ://doi.org/10.1093/eurpub/ckt075.

3. Galsworthy MJ, McKee M. Europe's 'Horizon 2020' science funding programme: How is it shaping up? J Health Serv Res Policy. 2013;18(3):182-5.

4. Chalmers I, Glasziou P. Avoidable waste in the production and reporting of research evidence. Lancet. 2009;374(9683):86-9.

5. Horizon 2020. https://ec.europa.eu/programmes/horizon2020/en. Accessed 7 May 2020.

6. EU Commission. Spreading excellence \& widening participation in Horizon 2020 - analysis of FP participation patterns and research and innovation performance of eligible countries, May 2018. https://ec.europa.eu/programmes/horizon2020/en/news/ widening-participation-horizon-2020-report-analysis-fp-parti cipation-patterns-and-ri.

7. CORDIS. https://cordis.europa.eu/projects/en. Accessed 3 June 2019.

8. Biomedical Research. http://www.alliedacademies.org/biomedical -research. Accessed 16 May 2019.

9. UK Clinical Research Collaboration Health Research Classification System. http://www.hrcsonline.net. Accessed 23 May 2020.

10. Digital Economy and Society Index Report 2018, Research and Innovation, European Commission. https://ec.europa.eu/ information_society/newsroom/image/document/2018-20/7 desi_report_research_and_innovation_-_horizon_2020_E2357 526-A51E-DCAD-71343D67E1A6B0A1_52242.pdf. Accessed 27 Dec 2019.

11. United Nations, Department of Economic and Social Affairs, Population Division. World Population Prospects: The 2017 Revision. www.Worldometers.info. Accessed 30 Aug 2019.

12. State portal of the Republic of Kosovo. https://www.rks-gov.net. Accessed 30 Aug 2019.

13. World Bank. http://data.worldbank.org/indicator/SP.POP.SCIE. RD.P6/countries. Accessed 21 Nov 2019.

14. World Bank. http://data.worldbank.org/indicator/GB.XPD.RSDV. GD.ZS/countries. Accessed 21 Nov 2019.

15. Microsoft Excel. Version 2010.

16. SAS Institute Inc. Cary, NC, USA. Software release 9.4.

17. Rauch M, Sommer-Ulrich J. Participation of the Central and Eastern European EU Member States in the 7th framework programme: analysis, evaluation, recommendations. Commissioned by the Federal Ministry of Education and Research (BMBF), 2012. http://www.fp7.cz/files/dokums_raw/moezsummaryfina 11_8121.pdf. Accessed 24 Feb 2019.

18. EU Commission. Interim Evaluation of Horizon 2020. Commission staff working document. https://op.europa.eu/en/publicatio n-detail/-/publication/fad8c173-7e42-11e7-b5c6-01aa75ed71a1/
language-en/format-PDF/source-77918455. Accessed 12 June 2019.

19. European Parliament. Overcoming innovation gaps in the EU-13 Member States. Study P/G/STOA/FWC/2013-001/LOT 8/C4 March 2018. http://www.europarl.europa.eu/RegData/etudes/ STUD/2018/614537/EPRS_STU(2018)614537_EN.pdf. Accessed 21 June 2019.

20. IEA, ISEE, EUPHA. Joint statement of the public health associations of Europe (IEA, ISEE, EUPHA) on the health research programme 2014-2015 (Horizon 2020) proposed by the European Commission. https://eupha.org/repository/publications/joint_state ment_IEA_ISEE_EUPHA_30_Sep_2013.pdf. Accessed 18 Feb 2020.

21. Smolders R, De Boever P. Perspectives for environment and health research in Horizon 2020: Dark ages or golden era? Int J Hyg Environ Health. 2014;217(8):89.

22. McCarthy M, Zeegers P. Public Health Innovation and Research in Europe: introduction to the supplement. Public Health Innovation and Research in Europe: introduction to the supplement Mark. Eur J Public Health. 2013;23(Suppl 2):2-5.

23. Grimaud O, McCarthy M, Conceição C. Strategies for public health research in European Union countries. Eur J Public Health. 2013;23(Suppl 2):35-8.

24. McCarthy M, Conceição C, Grimaud O, Katreniakova Z, Saliba A, Sammut M. Narkauskaité L Competitive funding and structures for public health research in European countries. Eur J Public Health. 2013;23(Suppl 2):39-42.

25. Conceição C, Grimaud O, McCarthy M, Barnhoorn F, Sammut M, Saliba A, Katreniakova Z, Narkauskaité L. Programmes and calls for public health research in European countries. Eur J Public Health. 2013;23(Suppl 2):30-4.

26. Zander B, Busse R. Is there enough research output of EU projects available to assess and improve health system performance? An attempt to understand and categorise the output of EU projects conducted between 2002 and 2012. Health Res Policy Syst. 2017;15(1):13.

27. Ernst K, Irwin R, Galsworthy M, Charlesworth K, Wismar M. Difficulties of tracing health research funded by the European Union. J Heath Serv Res Policy. 2010;15:133-6.

28. Galsworthy MJ, Hristovski D, Lusa L, Ernst K, Irwin R, Charlesworth K, Wismar M, McKee M. Academic output of 9 years of EU investment into health research. Lancet. 2012;380(9846):971-2.

29. Publication office of the European Union. EU Vocabolaries. https://op.europa.eu/en/web/eu-vocabularies/th-concept-schem e/-/resource/authority/euroscivoc/?target=Browse. Accessed 21 Nov 2019.

30. EU Commission.Coronavirus Global Response Pledging Conference https://www.consilium.europa.eu/en/policies/covid-19-coron avirus-outbreak-and-the-eu-s-response/covid. Accessed 22 May 2020.

31. EU Commission. Horizon Europe https://ec.europa.eu/info/sites/ info/files/horizon-europe-presentation_2018_en.pdf. Accessed 22 May 2020.

32. Abubakar I, Plasencia A, Barnighausen T, Froeschl G, Burton M, Cobelens F. Horizon Europe. Towards a European agenda for global health research and innovation. Lancet. 2019;393:1272-3.

Publisher's Note Springer Nature remains neutral with regard to jurisdictional claims in published maps and institutional affiliations. 